\title{
Research on Bayu Traditional Sports Development
}

\author{
Ming Yang1, Hao Guo' ${ }^{1}$, Jindong Chang1,2*, Yujie Shen ${ }^{1}$ \\ ${ }^{1}$ College of Physical Education, Southwest University, Chongqing, China \\ ${ }^{2}$ Institute of Education Policy, Southwest University, Chongqing, China \\ Email: changlai@163.com
}

Received 19 November 2014; revised 21 December 2014; accepted 28 December 2014

Copyright (C) 2014 by authors and Scientific Research Publishing Inc.

This work is licensed under the Creative Commons Attribution International License (CC BY).

http://creativecommons.org/licenses/by/4.0/

(c) (i)

\section{Abstract}

Bayu traditional national sport is non-material cultural heritage with local folk characteristics. Today, traditional sports development in Bayu areas affects various aspects which cannot be a good cause to inherit and carry forward. This paper studies the factors limiting its development from a regional, national and entertaining three aspects of the heritage value of the effective Bayu traditional sports and space to develop their survival and development which have to play a certain reference.

\section{Keywords}

\section{Bayu, National Traditional Sports, Development Status}

\section{Introduction}

Bayu area is one of the main gathering places which have minority nationality in our country. It is made up of the Han nationality, the Miao nationality, Tujia and other more than 50 nationalities and the population of minority nationality is about 1.8 million [1]-[3]. Tujia has the most minority nationality, and Miao is the second one. Because of its unique topography, Bayu region merges into an integral impact of ethnic culture, and then it creates a unified style of Bayu traditional minority national sports. Traditional ethnic sports cannot get proper propaganda, development and foreign exchange because of unprogressive economy, inconvenient traffic and so on. This thesis analyzes the interrelated characteristics of the traditional minority national sports culture. It summarizes and analyzes reasons in order to profitably carry forward Bayu region national traditional sports and arts [4].

${ }^{*}$ Corresponding author. 


\section{Overview of Bayu Traditional Culture}

\subsection{Bayu Traditional Culture}

Ethnic traditional culture refers to the specific nationality has created and accumulated civilized achievement in the history of practice activity; it is the important condition of national community survival and development. Bayu ethnic traditional culture mainly refers to the culture of Tujia and Miao nationalities. At present, under the impact of the heterogeneous cultures, Bayu minority nationality should not only keep the original indigenous culture, but also be creative to reconstruct the national culture.

\subsection{Characteristics of Bayu Traditional Culture}

- Rich and varied: Bayu ethnic area through hundreds of years of history and combination between humanity and nature, it makes Tujia, Miao nationality and other minority nationalities accumulate endlessly in practical experience of life, and accumulate rich and varied ethnic traditional culture.

- A long historical standing: Tujia and Miao nationality are the main minority nationality in Bayu area, which have been living in the areas of the southeast of Chongqing. Through years of history of granting, it created a variety of idiomatical national traditional culture, and always protects and inherits national traditional culture.

- Inclusive: Bayu minority nationality live in many mountain areas, thus it has formed scatter and gather. Long-term communication between all nationalities contact, thus the traditional national culture not only has unique flavor, but also is permeable and compatible with each other.

\section{Project Characteristics of Bayu Traditional Sports}

\subsection{Geographical Characteristics}

Most of Bayu region is mountain terrain; part of the region is flat. The difference in temperature is very small in Bayu region. Yangtze River and Wujiang River runs through it. Unique geographical position and climatic characteristics is the foundation of Bayu traditional sports culture. Because many national struggle against the natural survival and national character of the indomitable fighting, it create the regional characteristics of Bayu sports culture. Good personality of ancient people who live in Wujiang River is important condition for promoting the traditional sports. Bayu region is a multi-ethnic region composed of over fifty minorities. Tujia and Miao is the most populous, the main ethnic minorities. From the traditional sports project analysis of autonomous regions like Xiushan, Qianjiang, Pengshui and Shizhu, thus Tujia is the main territory on geographically. Tujia waving dance, martial arts and Xiushan lantern are the most representative projects [5]. Bayu national minority traditional sports is never exist independently, it is always closely related to military, farming religion and people's life, thus it forms a unity with local characteristics. Most of Bayu people concentrated living on high ground because of the influence of geographical condition. Insufficient productivity and inconvenient traffic lead to less amount of information about the outside world and narrow culture atmosphere. National sports culture must be with strong local characteristics and national features because of economic subsistence and geographic closeness. Because Bayu region is widespread and scattered, there are great differences about thought, culture and life among each nation [2]. Therefore, it formed variety of content and with local characteristics of national traditional sports. Even the same sports also have difference of containing the moral and skill in nation in different areas of life [6]. For instance, high foot movement is Tujia traditional sports, there are two kinds tall drama and high footlights, both of which are required to play together at the tournament were to foot tall, the difference is that the former is greater than competitive performances.

\subsection{National Characteristics}

Bayu region of minorities have the national customs, traditional sports closely integrated with the customs and mutual infiltration, which gradually make traditional sports have the features of local customs, promote the diversification of traditional sports and the development of their own progress. Traditional sports have enriched the content of folk-custom, some traditional sports also melt into traditional festivals, sacrifice, marriage customs and other activities. Traditional sports also included singing festival, festival, and celebration activities. Because of the change of history and regional culture blend, to some extent, Bayu sports inherited and retained a 
variety of ethnic cultural characteristics in the history [3]. Special living custom and culture of ancient contributed to the sports culture of its own unique national characteristics. Bayu traditional sports is the unique ethnic minority sports and represent our national spirit and culture, the most profound project has experienced the vicissitudes of history, it proved that the core role of the project in the national and the huge cultural, spiritual appeal because of no other nation assimilation, integration. Such as Tujia waving dance, which includes a migration, hunting, a former army dance, production and life dance. This dance reappears of the evolution of the social history of Tujia and production in daily life; it also has a distinct primitive religious color [1].

\subsection{Recreational Characteristics}

Most of traditional minority national sports in Bayu region are the physical fitness for the purpose of histrionic, recreational sports. Most of these activities are in spare time for celebrating good harvest, festival, and wedding reception, which make sports and entertainment become an organic whole to expand the joyful atmosphere. Bayu sports culture is rich and colorful, it can be divided into recreational activities, military activities and ritual activities, most of the activities are recreational activities [1] [6]. It is also common to many traditional ethnic sports characteristics. For example, snatch the firework is a recreational activity in dong minority; it is not only a way to communicate with each other, but also a way to be happy. These recreational sports can not only enrich national life, but also promote the emotional communication between nationalities. Bayu region minority not only love culture, has a passion for sports, but also can sing and dance well, thus formed the communication with each other, promoted each other, continuous development and progress of traditional sports and traditional culture. It made the national tradition sports have both the technical and artistic quality, which produced a high degree of unity in the integrated activities. It can keep fit and have fun [7]. Li minority have a special activity, called jump a bamboo pole, it is very beautiful with a variety of beautiful posture. The participants were asked to not only have a good physical coordination, and control ability, but also have high music accomplishment and solid skills of dance [8].

\section{Current Situation of Bayu Traditional Culture and Sports}

\subsection{Problems of Bayu Traditional Sports}

The reasons for the unsmooth and uneven development of ethnic minority traditional sports do not only lie in cultural factors or the inadequate attractiveness of the projects. There are other reasons that cannot be ignored.

Firstly, it is that the government adopts improper strategies. Government owns huge administrative resources, and has necessary decision-making powers on the protection, development and heritage of traditional ethnic sports.

Secondly, it is that the lack of relevant materials and the compilation. Traditional ethnic sports are mostly scattered in civil. Thus it is difficult to collect and sort the materials because of the terrain and inhabited customs.

Thirdly, it is that the unattractive way of development and heritage. Due to the lack of the necessary updating, improvement and packaging of arts form and cultural content, the activities are relatively simple without their unique highlights and styles.

Fourthly, it is that the lack of talents in special protection of the project culture. At present, there are few county-level national culture professionals of the five counties in Bayu area, let alone professionals in grassroots units of the villages. On the other hand, antiquated infrastructure and manifestation are also factors that influence its development. The young lack identity to traditional ethnic sports and interests in participating in the activities. So they do not understand the developmental value and historical connotation of the hand-waving dance. With the implementation of the West Development, the exchange and integration between Bayu ethnic traditional sports and mass sports has accelerated its entering a higher stage. At the same time, Bayu ethnic traditional sports are faced with the assimilation with the mass sports.

As we all know, most of the traditional sports projects with national characteristics and regional characteristics are taught through words and deeds, that is - the heir of the last generation inspires the next. Rare of them master the skills of each event through the materials. With the declining inheritors, the traditional ethnic sports do not receive due guarantee and emphasizing. Then there is a gap between Bayu ethnic traditional sports and the schools. Universities have a large number of research specialists and a high cultural level and research abili- 
ty. However, so far there has not been a research institute for traditional sports of minorities in Bayu area. At present, the scientific research on the traditional ethnic sports lies in a lower level, especially the systematic and further research. Also, the organization and research of the Bayu traditional ethnic sports theory start late, and lack power and intensity of research, so there is no influential treatise published. Government does not provide adequate support and protection. And there is not enough exchange and cooperation with the media [9]. These lead to the incongruity of the development between sport items and traditional ethnic culture.

Infrastructure has immeasurable impact on the use and development of the Minority Traditional Sports in a region. The weak infrastructure may increase the difficulties of carrying out, tracking and rescuing. The inconvenient transportation and frequent natural disasters are still problems for ethnic enclaves in Bayu area, which greatly influences the market information and the propaganda when developing. The historic and geographic environments have contributed to the minority traditional sports culture. Inheritance, performance and cooperation are the main factors. With the social development and progress, the deepening of reform and opening up, people's ideology constantly change. The social culture patterns continue to impact people's live in Bayu minorities, which lead to the constant friction between the local culture and social culture. At last, there are differences and disconnection between the two cultures.

\subsection{Development Planning of the National Traditional Sports in Bayu}

\subsubsection{Retain and Spread Local Traditional Sports Culture with Unique Geographical Conditions}

With mountains around, Sichuan's terrain is unique and complex [2], which limits the communication with the outside world to some extent, but it helps to reserve the original ecological projects and local culture. The Yangtze River and Wujiang River runs through it, the Wujiang basin is a natural advantage for spread and develop local culture. If construct a traditional minority national sports culture corridor with Chongqing as the origin, the Wujiang river basin as the core part, which has a unique flavor and attractive sports culture and downstream spread to more and more widely area. Thus unblocked a channel for the closed minority national sports culture and make it public to others. Spread along the channel to the downstream of Yangtze River to cultural and economic developed areas. It can not only play an effective role spread in spreading, but also can attract exchanges and cooperation with economic and cultural developed areas downstream. As is known to all, it is highly universal of global and national. If you want to make the national tradition sports more vitality and communicative, the only way is \maintain the original natural heritage. Therefore Wujiang culture corridor not only make full use of the unique geographical conditions, more in line with rivers, traditional minority national sports culture with rich and colorful cultural characteristics, and fully keeps the original local sports culture.

\subsubsection{Reflect the Regional Cultural Characteristics and Highlight the Characteristics of National Culture}

Bayu region is an area which gathered with many ethnic minorities. Tujia accounts for the vast majority. Tujia nationality is China's ethnic minority which is rich in cultural prosperity and has a relatively unique rich traditional sports project, such as dragon boat, martial arts, waving dance, lanterns and so on various interesting traditional items. Waving dance and martial arts is ingeniously integrated ornamental and keeping fit. Tujia nationality has formed a unique folk customs and traditional sports culture resources and positions in the southwest region and across the country [1] [2]. Cultural facilities need to be invested if achievement wants to be made on Wujiang traditional sports cultural corridor, the construction of national traditional sports culture facilities into urban construction planning must be taken into consideration. Such as carry out all kinds of courses which integrating the interesting and keeping fit together, and establish a place for traditional ethnic sports exercise in the urban and rural community. And arrange for professional performance and guidance. Improve the enthusiasm of the masses, and enlarging the propaganda and popularization of traditional sports culture, exercise in the full understanding of the cultural origin and art form the project contains.

\subsubsection{Create a National Traditional Sports Culture with the Aid of Government}

A complete system is the basis of external promotion of local sports, among which rules is the most important. It is the scale of people's communication, promotion and competition. Without a complete and strict system of rules, any sport is untenable.

If traditional sports grafted in school sports curriculum, with a more scientific and reasonable sports promo- 
tion to the society, the ethnic culture will reach a higher stage [3]. At the same time, we also need the national government as a solid backing; only in this way can the ethnic traditional sports reach a climax and peak. With the reform and opening up, the high-speed economic development, national traditional sports activity organization changed gradually from spontaneously to the direction of organized, planned. From a mere entertainment, sports develop in the direction of multi-function and deep-level. There are folk activities developed to tourism and cultural activities. With local features combined with modern means, focusing propaganda, interaction, Bayu region as the origin, the western China ethnic culture as the connotation, finally construct a minority nationality cultural corridor in the Wujiang river valley.

\section{Conclusions}

From the research and analysis of Bayu region traditional minority national sports cultural source, geographical features, folk custom and entertainment features put forward its own ideas and opinions. Main conclusions are the following:

- Bayu region is located in the Sichuan basin, and surrounded by mountains, because of natural geographical conditions. With a number of the most widespread of Tujia and Miao, it creates the original ecological and unique national traditional sports projects and sports culture.

- Bayu region of traditional minority national sports culture is closely combined with people's Daily life and production, through the vicissitudes of history incorporate a variety of factors, such as the religion and the military, thus forming a unity with strong local characteristics.

- To a great extent, Bayu region keeps the original ecological ethnic characteristics and nature of culture of the unique geographical condition, economic situation and communication with the outside environment, however, it also prevents the spread of traditional ethnic sports and foreign exchanges, and insufficient government support and protection also limit its inheritance and dissemination. We must reinforce personnel and government regulation, and take effective methods to diffuse, such as the Wujiang River basin culture corridor; it can combine the traditional sports with school curriculum effectively; it also can specifically set speaking, performance, teaching and professional talents and so on.

Above all, Bayu region traditional sports has good prospects for development, as long as it makes full use of its own advantages and improves the deficiencies, and improves related personnel training, equipment, sites, and foreign exchange, and then it can make local traditional sports and cultural transmission get high quality, and can allow more people to accept more Bayu national traditional sports.

\section{Acknowledgements}

This research was supported by "The Fundamental Research Funds for the Central Universities (Grant No. SWU1309231)” and “The Research Project of Chongqing Sports Bureau (Grant No. B201417)” and “The Humanities and Social Science Research Youth Foundation of the Ministry of Education in China (Grant No. 12YJC880005)” and “The Fundamental Research Funds for the Central Universities (Grant No. SWU1109071)” and “Chongqing Education Science Key Project Planning (2014-GX-002)” and “Chongqing Higher Education Reform Project (No. 120388)”.

Corresponding author Chang Jindong is a lecturer in the College of Physical Education at Southwest University and the vice-head of Institute of Education Policy. Here, the authors would like to express heartfelt thanks to anonymous peer reviewers and editors, your comments are important to our team that will be promoted our research forward.

\section{References}

[1] Liang, J.P. and Chang, J.D. (2006) Investigation of the Minority Traditional Sports and Cultural Resources. Chongqing Municipal Science and Technology Research Project Reports, Chongqing University of Posts and Telecommunications, Chongqing, 11-17.

[2] Pang, Y.N. (2001) Sports Development in Southwest Minority Studies. State Sports General Administration of Sports and Social Sciences, Soft Science Research Report, Southwest Normal University, Chongqing, 16-25.

[3] Wang, Y.Z. (2011) Study on the Bayu Sports Cultures. Sports Culture Guide, 3, 36-37.

[4] (2004) Research on Promoting the Shaping Tan Traditional Ethnic Sports Culture in College Physical Education. Kun- 
ming University of Technology (Social Sciences), 4, 88-90.

[5] Zhang, Y.L. and Wang, M.F. (2013) Study Chongqing Minority Protection Fighting Sports. Martial Science, 10, 7781.

[6] Feng, S.G. (2004) Value and Western Development Research on Minority Traditional Sports. Guizhou Normal University (Natural Science), 6, 87-92.

[7] Zhang, S.H. and Zhang, L. (2011) Review on the Safety of Traditional Sports and Cultural Development of Our National. Journal of Beijing Sport University, 34, 29-30.

[8] http://dbpub.cnki.net/grid2008/dbpub/detail.aspx?filename=SNAD000001315627\&dbname=SNAD

[9] http://dbpub.cnki.net/grid2008/dbpub/detail.aspx?dbname=SNAD\&filename=SNAD00000131937 
Scientific Research Publishing (SCIRP) is one of the largest Open Access journal publishers. It is currently publishing more than 200 open access, online, peer-reviewed journals covering a wide range of academic disciplines. SCIRP serves the worldwide academic communities and contributes to the progress and application of science with its publication.

Other selected journals from SCIRP are listed as below. Submit your manuscript to us via either submit@scirp.org or Online Submission Portal.
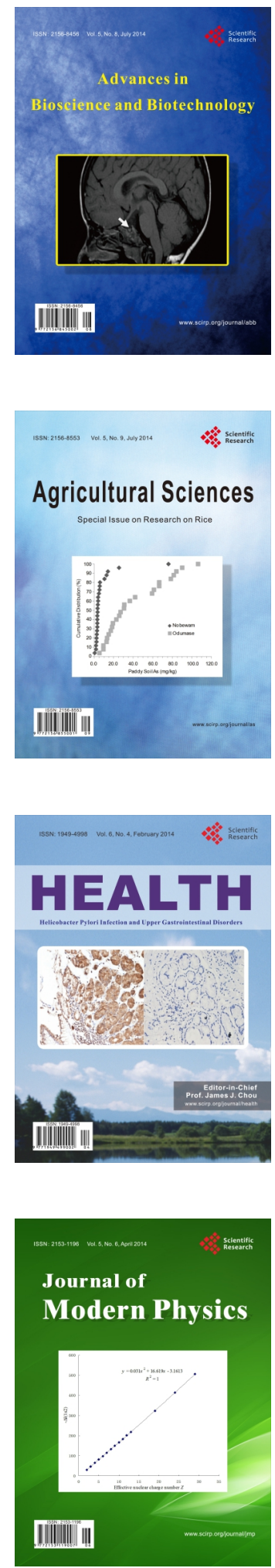
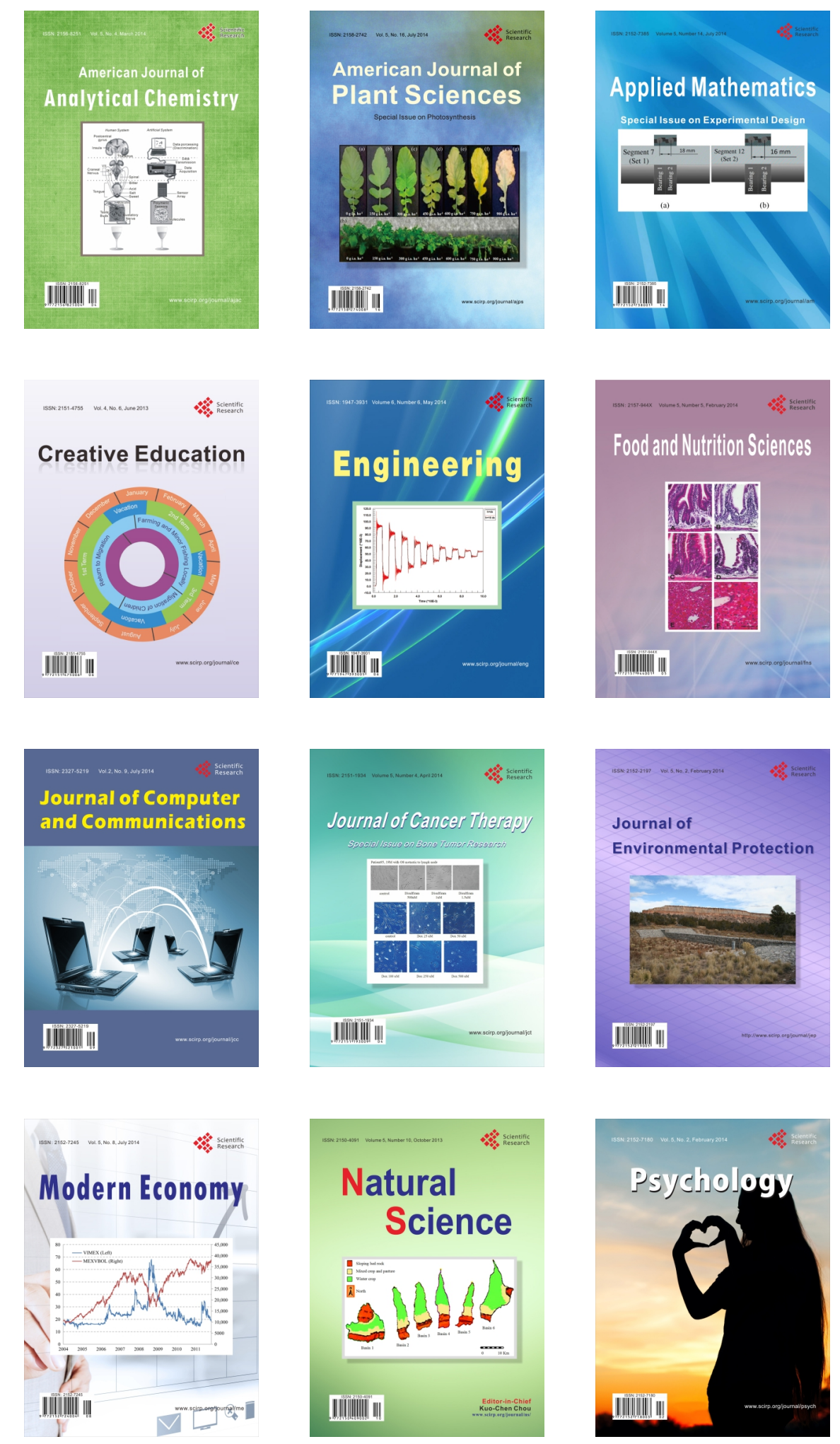